This is a peer-reviewed, accepted author manuscript of the following research article: Cresswell-Smith , J., Macintyre, A. K., \& Wahlbeck, K. (2020). Untapped potential? Action by nongovernmental organisations on the social determinants of mental health in high income countries: an integrative review. Voluntary Sector Review, 1-

21. https://doi.org/10.1332/204080520X15874661935482

\title{
Untapped potential? Action by non-governmental organisations on the social determinants of mental health in high income countries: an integrative review.
}

\section{Introduction}

Preventing mental ill health by reducing inequality, poverty and social isolation has been highlighted as an area of importance by the UN Human Rights Council (UN, 2017), which also recommends an end to the over-reliance on biomedical explanations of mental health difficulties and more focus on influence of the social, economic and cultural environment on mental health. The World Health Organisation (WHO) takes a similar stance stating; 'Mental health and many common mental disorders are shaped to a great extent by the social, economic, and physical environments in which people live' (World Health Organisation, 2014). These approaches place and greater emphasis on the social determinants of mental health which tend to follow a social gradient, meaning individuals with better circumstances in life also having higher levels of mental health and vice versa (Marmot, 2005; Allen, Balfour, Bell \& Marmot; Shim et al 2014; WHO \& Calouste Gulbenkian Foundaton 2014; Fisher \& Baum, 2010). Tackling this social gradient has become a topic for attention within the mental health sector as we are unlikely to improve population mental health without also addressing the daily circumstances in which we live (Alegría, 2018).

The voluntary sector's role in addressing the social determinants of health has been explored by the UCL Institute of Health Equity in relation to seven areas; family, friends and communities, education and skills, good work, money and resources, housing, and surroundings (Daly \& Allen, 2017). Research (outlined below) indicates 
This is a peer-reviewed, accepted author manuscript of the following research article: Cresswell-Smith , J., Macintyre, A. K., \& Wahlbeck, K. (2020). Untapped potential? Action by nongovernmental organisations on the social determinants of mental health in high income countries: an integrative review. Voluntary Sector Review, 1-

\section{1. https://doi.org/10.1332/204080520X15874661935482}

that these areas are also relevant for mental health. The aim of this paper is to set out evidence on how NGO actions impact the social determinants of mental health, and to raise topical questions around their role in mental health promotion. Illuminating the actions in this light may be of relevance for research, policy and practice.

The protective nature of the family has been well-documented in terms of mental health (Thomas, Liu \& Umberson, 2017) although social and economic inequalities have been found to complicate this effect. A comprehensive review by Reiss (2013), reports that children from socioeconomically disadvantaged families are up to three times more likely to develop mental health difficulties than their peers from socioeconomically advantaged families. In this case attention is needed not only on appropriate mental health services for the children question, but also on how to support families to better meet their children's' needs, offset the social gradient, and be the protective factor in their children's lives. Paying attention to contextual factors such as community and environmental stress within tailored parenting interventions has shown promise (Stewart-Brown \& Schrader-McMillan, 2011).

Friendships and communities have been linked to mental health in different ways. For example, social capital has been suggested as a strong determinant of selfrated health and psychological wellbeing (Nieminen et al., 2010) and loneliness has been associated with many negative mental health outcomes (Victor \& Yang, 2012). Social disadvantage, including low income and a lack of household and neighbourhood resources, can make forming and maintaining friendships difficult for both children and adults (Kearns, Whitley, Tannahill \& Ellaway, 2015; Matthews \& Besemer, 2014). Social connectedness can be supported by nurturing social contacts and supporting 
This is a peer-reviewed, accepted author manuscript of the following research article: Cresswell-Smith , J., Macintyre, A. K., \& Wahlbeck, K. (2020). Untapped potential? Action by nongovernmental organisations on the social determinants of mental health in high income countries: an integrative review. Voluntary Sector Review, 1-

21. https://doi.org/10.1332/204080520X15874661935482

social inclusion, both of which are particularly important to develop within disadvantaged communities (Cruwys et al., 2014; Small, 2010).

Education has been established as a leading social determinant of mental health (Shim, et al., 2014; Silva, Loureiro, \& Cardoso, 2016) and universal access to education has demonstrated far reaching influences over the life course (Birdsall, Levine, \& Ibrahim, 2005; OECD, 2012). Although the primary focus should undoubtedly be placed on making education accessible to all of society, work is also needed to better address inequalities for those within the education system. Children from disadvantaged socioeconomic backgrounds are more likely to suffer mental health difficulties, and are at higher risk of lower attainment and of dropping out of the education system (OECD, 2012). School-based approaches may therefore offer opportunities for reducing these risks and tackling the social gradient (Weare, 2010).

Evidence of working life as a determinant of mental health has been portrayed in studies demonstrating detrimental effects of difficult work environments (Harvey, Henderson, Lelliott \& Hotopf, 2009; Bhavsar \& Bhugra 2008). Supporting mental health at the workplace may involve many different approaches including building more mental healthy policies (WHO, 2005). Likewise, money and resources has been found to impact mental health, with broad interventions for reducing the detrimental impacts of poverty (Elliot, 2016), income inequality (Pickett, \& Wilkinson, 2010), and financial debt (Jenkins, Fitch, Hurlston \& Walker, 2009) showing potential in terms of addressing negative mental health outcomes. A significant gap in mental health between areas of higher or lower disadvantage has been reported, with material and psychosocial factors assumed to underpin this gap (Mattheys et al., 2016). 
This is a peer-reviewed, accepted author manuscript of the following research article: Cresswell-Smith , J., Macintyre, A. K., \& Wahlbeck, K. (2020). Untapped potential? Action by nongovernmental organisations on the social determinants of mental health in high income countries: an integrative review. Voluntary Sector Review, 1-

21. https://doi.org/10.1332/204080520X15874661935482

Housing difficulties and poor quality housing also follows a social gradient, and has been linked to poor mental health (Mason, Baker, Blakely, \& Bentley, 2013; Savage, 2016; EUROSTAT, 2018). Improving housing conditions has shown positive impacts on mental health outcomes (Curl et al., 2015). The environment we live in has been found to influence mental health (Townsend \& Weerasuriya, 2010; Helbich, 2018) and enhancing possibilities for social interaction and access to green (vegetation) and blue (water) spaces may support mental health (Lee \& Maheswaran, 2010; Breedvelt, 2016). Green space may buffer against the negative health and mental health impacts of stressful life events (Berg et al, 2010).

Many of the social determinants of mental health, and the interventions designed to address them, lie outside of the health sector (Wahlbeck, 2015; Jané-Llopis et al.,2011; Forsman, 2015). The Mental Health in All Policies (MHiAP) approach tackles determinants across sectors and encourages synergies between sectors. MHiAP highlights the need for systematically assessing the mental health implications of policy actions in all sectors (Joint Action on Mental Health and Well-being, 2017; WHO, 2013; WHO, 2014). However, MHiAP has largely focused on public sector actions so far, and less on the role of civil society (Joint Action on Mental Health and Well-being, 2017). Civil society actions can be organised in different ways, for example via NonGovernmental Organisations (NGOs) which range from small volunteer-led, participatory organisations with limited financial resources, to large charities with thousands of staff and volunteers (Greer, Kosinska, \& Wismar, 2017; Jareg, \& Kaseje, 1998). NGOs often operate in diverse roles such as advocacy, health promotion, public interest campaigning, social community activities and service delivery (Greer, Kosinska, \& Wismar, 2017; Karlsson, \& Markström, 2012; Markström \& Karlsson, 
This is a peer-reviewed, accepted author manuscript of the following research article: Cresswell-Smith , J., Macintyre, A. K., \& Wahlbeck, K. (2020). Untapped potential? Action by nongovernmental organisations on the social determinants of mental health in high income countries: an integrative review. Voluntary Sector Review, 1-

21. https://doi.org/10.1332/204080520X15874661935482

2013). Success within the NGO sector has been attributed to their unique position in society, (Butler et al 2017; Artaraz, Thurston, \& Davies, 2007; Gentry, Powers, Azim \& Maidrag 2018), which also places them in a good place for shaping social policy and impacting the social determinants of health and mental health (WHO, 2007). NGOs' approachability, flexibility, partnership working, and user involvement, particularly in relation to hard to reach groups, contribute to their unique potential (Flanagan, \& Hancock, 2010).

NGO's can be seen to work with a broad range of societal matters, and it would therefore seem helpful to explore how NGO's outside of the health sector may inadvertently contribute towards mentally healthy daily environments. By teasing out these actions we acknowledge the importance of addressing mental health across all policy areas, and extend the MHiAP approach to include the voluntary sector.

\section{Methods}

We undertook an integrative review, based on iterative searches identifying recent literature on NGO actions on the social determinants of mental health. The integrative review format, suitable for exploring emerging topics and stimulating new research was found to be the most appropriate methodological framework for our review (Torraco, 2016). We used the same seven areas (family, friends and communities, education and skills, good work, money and resources, housing, and surroundings) as Daly and Allen (2017) as it provided a good base for examining the social determinants of mental health.

The two stepped search process started with a broader centralised search using Web of Science (which includes Science Citation Index Expanded; Social Sciences Citation 
This is a peer-reviewed, accepted author manuscript of the following research article: Cresswell-Smith , J., Macintyre, A. K., \& Wahlbeck, K. (2020). Untapped potential? Action by nongovernmental organisations on the social determinants of mental health in high income countries: an integrative review. Voluntary Sector Review, 1-

21. https://doi.org/10.1332/204080520X15874661935482

Index; Arts \& Humanities Citation Index and Emerging Sources Citation Index) and EBSCOhost (including CINAHL; Academic Search Elite; SocINDEX with Full Text;

GreenFILE; Library; Information Science \& Technology Abstracts; AgeLine;

PsycInfo). Bibliographic searches were performed during the months November 2017 to August 2018, covering years 2007-2017. We considered only English language publications.

Search terms were chosen to cover the different social determinants of mental health including various combinations of the following terms and their synonyms; “mental health”, “mental wellbeing”, “civil society”, "civic society”, “charities, “nongovernment organisation", "NGO", "not-for-profit", "voluntary organisation", “community organisation”, “determinants", “upstream”, "policy”, “drivers," "socioeconomic", “risk factors", “protective factors", "predictors”, “housing”, “poverty”, “inequality”, “employment”, “jobs”, “unemployment”, education”, ”schools”, “health care", "service", "provider".

Although this initial search strategy resulted in a total of 917 articles, very few were focused on NGO actions. Consequently, a second search was performed using Google Scholar including terms listed above, as well as words depicting Daly and Allens (2017) seven key areas of interest; "family", "friends and communities", "education and skills", "work", "money and resources", "housing" and "surroundings" in conjunction with mental health determinant search terms listed above.

We included original studies, reviews and grey literature covering NGO actions on mental health determinants. In order to ensure a focus on the social determinants of mental health, NGO actions which were interpreted as being mental health or recovery 
This is a peer-reviewed, accepted author manuscript of the following research article: Cresswell-Smith , J., Macintyre, A. K., \& Wahlbeck, K. (2020). Untapped potential? Action by nongovernmental organisations on the social determinants of mental health in high income countries: an integrative review. Voluntary Sector Review, 1-

21. https://doi.org/10.1332/204080520X15874661935482

services, or those specifically targeting people with mental health problems or disorders were omitted, as were NGO actions which were considered to be development work.

Results were summarised according to what data was available and extracted in Appendix 1.

\section{Results}

The first step in the search process produced 917 papers, with only 9 papers meeting the inclusion criteria. Following additional searches using Google Scholar, a further 17 papers were found resulting in a final 26 papers included in the current review, summarised in Appendix 1. The included papers are almost exclusively from high income countries, including articles from UK, Portugal, Sweden, Holland, as well as Canada, USA and Australia, in addition to a few with a global and/or European focus. Only 6 out of the 26 articles were produced solely by NGO's with the majority being produced in collaboration with academic or statutory services.

\section{Families}

A recent rapid review of the benefits and risks of voluntary sector work with vulnerable families found it to be well matched with family needs, and well placed for service user advocacy (Butler, McLaughlin, Hayes, \& Percy, 2017). Family support organised by NGOs may improve a host of outcomes including mental wellbeing for both children and parents. Examples include targeted (volunteer administered) home visiting schemes offering support, friendship and practical help to families under stress, helping to prevent family crisis (Hermanns, Asscher, Zijlstra, Hoffenaar, \& Dekovič, 2013; van Aar, Asscher, Zijlstra, Deković, \& Hoffenaar, 2015). Positive changes from these studies include long term improvements in parental wellbeing and competence as 
This is a peer-reviewed, accepted author manuscript of the following research article: Cresswell-Smith , J., Macintyre, A. K., \& Wahlbeck, K. (2020). Untapped potential? Action by nongovernmental organisations on the social determinants of mental health in high income countries: an integrative review. Voluntary Sector Review, 1-

21. https://doi.org/10.1332/204080520X15874661935482

well as diminished behavioural difficulties on the part of the child. Parenting programmes delivered within the voluntary sector have also reported improvements in child problem behaviour, play, sibling behaviour, despite facilitators not being specialised in mental health per se. (Gardner, Burton, \& Klimes, 2006).

\section{Friends and Communities}

Befriending, i.e. emotional support provided by volunteers (Thompson, Valenti, Siette, \& Priebe, 2016), has been shown to have a modest effect on psychological distress as well as depressive symptoms (Mead, et al., 2010). Mentoring actions i.e. a structured and trusting relationship between a mentor, (with more experience) and a protégé, has been successfully implemented by NGOs to promote mental health and prevent mental health problems (Larsson, Pettersson, Skoog, \& Eriksson, 2016).

UK-based research indicates that community engagement often includes health promotion via informal NGO actions such as exercise, cooking, social, arts and creative activities (Jones, Kimberlee, Deave, \& Evans, 2013). Creative art programmes which were shaped by local conditions and local people were found to be effective in improving mental wellbeing (Cameron, Crane, \& Ings, 2012) offering potential for cross sector collaborations (Cameron et al. 2013). Framing activities in terms of fun, leisure, creativity and socialising (as opposed to illness prevention) produced positive results on mental wellbeing among other health benefits (Jones, Kimberlee, Deave, \& Evans, 2013). In disadvantaged communities, NGOs may be needed to bring in new sources of knowledge and to access novel options (Barry, Clarke, Jenkins, \& Patel, 2013). 
This is a peer-reviewed, accepted author manuscript of the following research article: Cresswell-Smith , J., Macintyre, A. K., \& Wahlbeck, K. (2020). Untapped potential? Action by nongovernmental organisations on the social determinants of mental health in high income countries: an integrative review. Voluntary Sector Review, 1-

21. https://doi.org/10.1332/204080520X15874661935482

\section{Education and skills}

NGOs undertake different types of work in school settings including the provision of counselling, mental health promotion and running emotional literacy programmes for disadvantaged groups (Spratt, Shucksmith, Philip, \& Watson, 2007). NGO's can be part of a holistic approach to supporting mental wellbeing in schools, one example being Targeted Mental Health in Schools Project (TaMHS) in the UK which linked up schools, local authority services, health trusts and the voluntary sector to support mental health within the school environment (Department for Children, Schools and Families, 2008). Benefits of NGO actions in schools include more informal support approaches for young people, such as peer support, mental health training for teachers, and the importance of including young people themselves in developing person centred approaches (Mental Health Foundation, 2007). Collaborative initiatives around antibullying campaigns have been reported to produce positive outcomes including enhanced social capital, promotion of mental and physical health, promotion of healthy relationships, school engagement, and prevention of crime (Craig \& Pepler, 2007).

\section{Good Work}

Evidence on non-mental health NGOs taking action on work as a determinant of mental health is limited. One example is a state-level cross-sectoral collaboration in Australia to support the mental health of farmers in response to a severe drought (Fragar et al., 2008). This collaboration emphasised that improving mental health cannot be achieved in the health sector alone and identified a range of necessary agencies and NGOs. The study also indicated that it is possible for non-mental health NGOs (such as professional associations) to lead broad mental health actions (Fragar, Kelly, Peters, Henderson, \& Tonna, 2008). Additionally, collaboration between the statutory 
This is a peer-reviewed, accepted author manuscript of the following research article: Cresswell-Smith , J., Macintyre, A. K., \& Wahlbeck, K. (2020). Untapped potential? Action by nongovernmental organisations on the social determinants of mental health in high income countries: an integrative review. Voluntary Sector Review, 1-

21. https://doi.org/10.1332/204080520X15874661935482

Jobcentre (UK) and other organisations including NGO's report positive outcomes of voluntary work during periods of unemployment (Newton, 2012). Participants reported that these actions had a strengthening impact on their mental health, equipped them better for life in the future, and reduced barriers to work.

\section{Money and Resources}

NGOs working on poverty and inequality have a clear role to play in addressing mental health, requiring action across all sectors (Jenkins, Fitch, Hurlston, \& Walker, 2009). The Money Advice Liaison Group (MALG) is a diverse range of public, private and voluntary sector organisations who provides money advice guidelines in the UK, also in the context of mental health difficulty (Mental Health and Debt Guidelines). A further example of debt organisations acknowledging mental health is work by Credit Counselling Service (CCCS), a national debt charity in the UK which refers clients for a wellbeing assessment and psychological support (Bell, 2012). This debt relief NGO forms a cross-sector coalition between money advice organisations and mental health organisations advocating for improved support of people experiencing debt and poor mental health. Other UK charities have also have highlighted the link between money, resources and mental health, such as between austerity policies in EU member states and increases in suicide rates (Samaritans, 2017).

\section{Housing}

Housing NGOs such as Shelter UK highlight the detrimental effects of poor housing not only in terms of availability and affordability, but also in terms of housing conditions (Smith, Albanese, \& Truder, 2014). According to Shelter UK, 1 in 5 adults in the general population report housing issues to have negatively impacted their mental 
This is a peer-reviewed, accepted author manuscript of the following research article: Cresswell-Smith , J., Macintyre, A. K., \& Wahlbeck, K. (2020). Untapped potential? Action by nongovernmental organisations on the social determinants of mental health in high income countries: an integrative review. Voluntary Sector Review, 1-

21. https://doi.org/10.1332/204080520X15874661935482

health in the last 5 years, with 3 out of 10 these stating that they had not had any mental health difficulty previous to the housing problem (Shelter, 2017).

NGO interventions such as advocacy and practical improvements have shown promising results, for example those in receipt of fuel poverty interventions are up to $40 \%$ less likely to report high levels of psychological distress (Green \& Gilbertson, 2008). NGOs also highlight the knock-on effects of poor housing which may force people into trade-off's for between basic needs (Cooper, Purcell, \& Jackson, 2014).

\section{Our surroundings}

Civil society and the environmental movement often play a crucial role in protecting and defending green and blue spaces (Shandas \& Messer, 2008) but often to fail to recognise the positive population mental health impact that preservation and restoration of ecological habitats may have.

\section{Discussion}

Our results report the different ways in which NGO actions reach the daily lives of people in many contexts and tap into the social determinants of mental health. These actions support the notion that responsibility for addressing the social determinants lies not only on health services, but on society as a whole (Johnson, 2017). In a high income context, this is more likely to mean reducing the impact of the social gradient in relation to individual determinants than increasing access to certain services (e.g. universal education).

Disadvantaged families may have increased risk of mental health difficulties. Although family support may be part of statutory services in high income countries, 
This is a peer-reviewed, accepted author manuscript of the following research article: Cresswell-Smith , J., Macintyre, A. K., \& Wahlbeck, K. (2020). Untapped potential? Action by nongovernmental organisations on the social determinants of mental health in high income countries: an integrative review. Voluntary Sector Review, 1-

21. https://doi.org/10.1332/204080520X15874661935482

NGO's also make valuable contributions. Home visiting schemes and practical support have showed improvements in both parental and child wellbeing. The way in which NGO's approach this type of support may be one reason behind their success. NGO's may for example offer less formal support in comparison to statutory services reducing barriers, and nurture unique connections. People working in mental health NGOs have been found to show more positive attitudes towards people with mental illness compared to those working within statutory services (Rose, von Hippel, Brener, \& von Hippel, 2018), which may potentially have a reciprocal effect.

Having the freedom to tailor activities to reflect local circumstances, as well as employing participatory processes may also contribute to such unique connections (Cameron, Crane, \& Ings, 2012). Our results indicate that NGO actions which develop informal friendships and participation in the community contribute towards prevention of loneliness, strengthen self-esteem, confidence, and trust. This is also true in terms of framing community mental health promotion as fun leisurely activities.

The current review included studies from high income counties and as such access to education and skills was generally assumed to be universal. Focus was therefore placed more on how the mental health gradient can be alleviated within educational settings. Children from disadvantaged backgrounds not only have a higher chance of under attainment in school (OECD, 2012) but are also more likely to have fewer social, emotional, language and literacy skills, and an increased risk of behavioural problems (Marmot 2015). By supporting emotional literacy in school, and reducing adverse factors such as bullying (Craig \& Pepler, 2007) NGOs are able to address these risks to mental health. The benefits of including NGO's in the school environment include transferring the ethos and values as well as innovative working 
This is a peer-reviewed, accepted author manuscript of the following research article: Cresswell-Smith , J., Macintyre, A. K., \& Wahlbeck, K. (2020). Untapped potential? Action by nongovernmental organisations on the social determinants of mental health in high income countries: an integrative review. Voluntary Sector Review, 1-

21. https://doi.org/10.1332/204080520X15874661935482

models from NGOs into educational settings. However, this is not without its own challenges as power dynamics between schools and voluntary organisations may at times be problematic (Spratt et al.,2007). Collaboration may be complicated by tensions resulting from individual support to particular students versus addressing the wider school environment, as well as schools being inclined to prioritise educational attainment while NGOs may hold a stronger mental health focus (Spratt, Shucksmith, Philip, \& Watson, 2007). Such differences will need to be attended to in order to ensure long-term success. Our results also indicated participatory processes to be useful when developing successful actions within the education setting.

It was difficult to locate NGO actions to support mental health in the work context, even though it is an important social determinant of mental health both in terms of obtaining the economic stability needed for mental health and wellbeing, and in terms of participation. Good examples outlined in our results relied on partnership working, which may be especially important considering the knock-on effects from one social determinant of mental health to another (Flanagan, \& Hancock, 2010). Results also highlight the benefits of non-mental health organisations such as employment services including mental health components in their support packages.

Partnership working was also found to be useful in relation to support around money and resources, which requires expertise from quite diverse domains. Crosssectoral partnerships have been found useful when working on ameliorating socioeconomic disadvantage (Wahlbeck, Cresswell-Smith, Haaramo, \& Parkkonen 2017). Likewise, in the context of housing, successful collaborations incorporated a broad set of stakeholders such as central and local government, fuel utilities, housing providers, consumer groups and voluntary organisations whose primary focus was 
This is a peer-reviewed, accepted author manuscript of the following research article: Cresswell-Smith , J., Macintyre, A. K., \& Wahlbeck, K. (2020). Untapped potential? Action by nongovernmental organisations on the social determinants of mental health in high income countries: an integrative review. Voluntary Sector Review, 1-

21. https://doi.org/10.1332/204080520X15874661935482

outside of the mental health sector (National Energy Action). It was difficult to find literature in terms of mental health and how NGOs impact our surroundings. Climate change is a more recently defined influencing factor on mental health (Berry, Bowen \& Kjellstrom, 2010), and broad collaborations may also be useful in this context.

Collaborative approaches including statutory services, public health organisations, meteorological services has been outlined as important, as has a community approach including NGO's and other civil society actors (Hayes, Berry \& Ebi 2019; Watts et al., 2018). This area holds potential for further research as little was found in this context within the time range stipulated by the inclusion criteria.

NGOs appear to be ideally positioned in order to inspire participation and civil engagement and are often located in the hearts of communities. In mental health NGOs, these actions tend to be developed in relation to empowering people with lived experience of mental health difficulties. Empowering participation in relation to the social determinants of mental health requires engagement from a broader set of stakeholders. Although NGO advocacy in relation to the social determinants of mental health remains under-explored, one notable example of this type of work is the engagement of civil society (including NGOs and other actors) in developing Canada's national mental health strategy (Mulvale, Chodos, Bartram, MacKinnon, \& Abud, 2014). The involvement of these organisations led to the revision of a draft policy with increased emphasis on the prevention of mental health difficulties and promotion of mental health, as opposed to primarily focusing on mental health service provision (Mulvale, Chodos, Bartram, MacKinnon, \& Abud, 2014). This suggests that civil society can be effective in shifting policies towards 'upstream' or social determinants of mental health. 
This is a peer-reviewed, accepted author manuscript of the following research article: Cresswell-Smith , J., Macintyre, A. K., \& Wahlbeck, K. (2020). Untapped potential? Action by nongovernmental organisations on the social determinants of mental health in high income countries: an integrative review. Voluntary Sector Review, 1-

21. https://doi.org/10.1332/204080520X15874661935482

NGOs positions are not always easy to negotiate. NGO actions are first and foremost defined by what the national government wants from civil society, and what level of influence it has over civil society actions (Greer, Kosinska, \& Wismar, 2017). A careful balancing act appears to be in motion between NGOs maintaining autonomy and benefitting from governmental buy-in, raising questions around how unbiased citizen-led NGOs can be if reliant on state funding (Greer, Kosinska, \& Wismar, 2017). This juxtaposition also rings true in terms of visibility of their actions. The relative lack of research on NGO actions in relation to the social determinants of mental health may encourage a discrepancy between the activities undertaken by NGOs and what is made visible. This may mean that although NGOs are often required to report outcomes to funders and other governing bodies, there may be less room evaluations suitable for academic publication. It is also noteworthy that only six out of the total of twenty-six articles included in the current study were solely produced by NGOs. The majority of the articles were produced in collaboration with academic or statutory services. This may reflect a general lack of NGO resources to be able to produce and publish literature of this kind, or alternatively may suggest improved collaborative initiatives. A drive towards more Community Engaged Research has been a topic for discussion also elsewhere (Battaglia et al, 2019). While NGO involvement in areas such as global health research has increased in recent years (Zachariah et al. 2010), these contributions will be best achieved through partnerships based on effective communication, transparency in decision-making, mutual respect, and trust (Oliver et al, 2016). Collaboration in this sense holds great potential for further research.

NGOs accomplish a range of positive actions, although they are rarely considered within the context of social determinants of mental health, and their potential 
This is a peer-reviewed, accepted author manuscript of the following research article: Cresswell-Smith , J., Macintyre, A. K., \& Wahlbeck, K. (2020). Untapped potential? Action by nongovernmental organisations on the social determinants of mental health in high income countries: an integrative review. Voluntary Sector Review, 1-

21. https://doi.org/10.1332/204080520X15874661935482

runs the risk of going un-tapped. The current review found it challenging to locate material detailing NGO actions which support social determinants of mental health although this does not mean that the work is not being done but may indicate a lack of and/or inconsistencies in reporting such results. Furthermore, the mental health benefits of many actions may be difficult to measure. For example the relationship between the environment and mental health is often difficult to establish as these relationships tend to be influenced by multiple factors including attributes of the environment and the individual (Lee \& Maheswaran, 2010). Supporting NGOs to showcase their actions makes them more visible, and allows them to be more readily translated into policy which can potentially improve equity, community engagement and participation (Delisle, Roberts, Munro, Jones, \& Gyorkos, 2005). Increased visibility strengthens the case for developing population mental health via actions on the social determinants mental health in line with the current paradigm shift. This review found it (at times) difficult to distinguish actions on the social determinants of mental health from NGO based service provision. Untangling this grey zone could be a useful endeavour and subject for further study.

\section{Strengths and limitations}

A leading strength of the current review is its focus on social determinants of mental health, building on previous work by Daly and Allen (2017). By only including NGO actions which impacted social determinants of mental health, the current review emphasises how mental health can be developed within the daily life. This approach is highly topical and reflects the current paradigm shift called for by the United Nations 
This is a peer-reviewed, accepted author manuscript of the following research article: Cresswell-Smith , J., Macintyre, A. K., \& Wahlbeck, K. (2020). Untapped potential? Action by nongovernmental organisations on the social determinants of mental health in high income countries: an integrative review. Voluntary Sector Review, 1-

21. https://doi.org/10.1332/204080520X15874661935482

and WHO as outlined in the leading paragraph. This approach also underlines the importance of this kind of work in terms of addressing the social gradient and acknowledges benefits of partnership working across sectors.

Finding the right way to review the literature was a challenge. The iterative method permitted by an integrative approach meant that sole reliance on conventional academic databases was not always possible, making systematic searches problematic. This less stringent process may have resulted in some material being missed although it did reach material produced by or in collaboration with NGOs. Although the results are in no way exhaustive this flexible approach provided a good starting point for further research, and highlighted how heterogeneous material in this line of enquiry is today.

Only English language searches were made, which limited our focus to English speaking contexts. There are undoubtedly also good examples of NGO actions in nonEnglish speaking countries which could have benefitted this review.

\section{Conclusion}

Although NGO actions produce considerable benefits to society, the full potential of these actions arguably remain untapped, under recognised and under used. More explicit exploration of how NGOs may ameliorate social determinants of mental health is timely considering current progress and focus on this line on enquiry elsewhere. By deliberately placing focus on actions outside of mental health services, the current review highlights how non mental health organisations may contribute towards positive mental health outcomes, inching towards a "Mental Health in All Policies" approach also within civil society. 
This is a peer-reviewed, accepted author manuscript of the following research article: Cresswell-Smith , J., Macintyre, A. K., \& Wahlbeck, K. (2020). Untapped potential? Action by nongovernmental organisations on the social determinants of mental health in high income countries: an integrative review. Voluntary Sector Review, 1-

21. https://doi.org/10.1332/204080520X15874661935482

It is clear that NGO actions do not exist in a vacuum but are impacted by a myriad of political and structural factors. This raises critical questions about the role of NGOs in taking action on the social determinants of mental health, whose responsibility it is, whether there is a need to frame these actions in terms of mental health, and whether it is possible to facilitate cross- and intra-sector collaborations for the benefit of population mental health. Facilitating NGOs, as well as making use of their knowledge and position in society without compromising on their autonomy and civil society roots may be a worthwhile undertaking, considering their broad potential in terms of their unique position in the community.

\section{References}

Alegría, M., NeMoyer, A., \& Falgàs Bagué, I. et al. (2018) Social Determinants of Mental Health: Where We Are and Where We Need to Go. Curr Psychiatry Rep, 20:95.

Allen J, Balfour R, Bell R, \& Marmot M. (2014) Social determinants of mental health, International Review of Psychiatry, 26(4);392-407

Artaraz, K., Thurston, M. \& Davies, S. (2007) Understanding family support provision within the local context of prevention: A critical analysis of a local voluntary sector project. Child \& Family Social Work, 12(4), 306-315.

Barry, M. M., Clarke, A. M., Jenkins, R., \& Patel, V. (2013). A systematic review of the effectiveness of mental health promotion interventions for young people in low and middle income countries. BMC Public Health, 13, 835.

Battaglia, T. A., Pamphile, J., Bak, S., Spencer, N., \& Gunn, C. Connecting Community to Research: A Training Program to Increase Community Engagement in Research. Prog Community Health Partnersh. 2019:13(2), 209-217. doi.org/10.1353/cpr.2019.0021 
This is a peer-reviewed, accepted author manuscript of the following research article: Cresswell-Smith , J., Macintyre, A. K., \& Wahlbeck, K. (2020). Untapped potential? Action by nongovernmental organisations on the social determinants of mental health in high income countries: an integrative review. Voluntary Sector Review, 1-

21. https://doi.org/10.1332/204080520X15874661935482

Bell, G. (2012). Online identification and referral for debt and mental health issues. Journal of Public Mental Health, 11(1), 32-38.

Berry, H.L., Bowen, K. \& Kjellstrom, T. (2010) Int J Public Health, 55: 123. https://doi.org/10.1007/s00038-009-0112-0

Bhavsar, V., \& Bhugra, D. (2008) Globalization: Mental Health and Social Economic Factors. Global Social Policy, 8(3), 378-396.

Birdsall, N., Levine, R. \& Ibrahim, A. (2005) Towards Universal Primary Education: investments, incentives, and institutions. European Journal of Education, 40: 337-349

Breedvelt, J.F. (2016). Psychologically Informed Environments: A Literature Review. Mental Health Foundation: London

Butler, M., McLaughlin, A., Hayes, D., \& Percy, A. (2017) Using the voluntary sector to provide services to children and families with complex needs as an alternative to social work services- what are the benefits and risks? Belfast: Queens University Belfast.

Cameron, M., Crane, N., \& Ings, R. (2012) Be creative, be well: Arts, wellbeing and local communities: An evaluation | Repository for Arts and Health Resources. (n.d.). Retrieved 20 March 2018, from http://www.artshealthresources.org.uk/docs/be-creative-be-well-arts-well-beingand-local-communities-an-evaluation/

Cameron, M., Crane, N., Ings, R., \& Taylor, K. (2013) Promoting well-being through creativity: how arts and public health can learn from each other. Social Studies of Science, 133(1).

Cooper, N., Purcell, S., \& Jackson, R. (2014) Below the breadline: the relentless rise of food poverty in Britain. Church Action on Poverty, Oxfam GB, and Trussell Trust. Retrieved 5 June 2018 from https://www.trusselltrust.org/wpcontent/uploads/sites/2/2016/01/Below-the-Breadline-The-Trussell-Trust.pdf

Craig, W. M., \& Pepler, D. J. (2007). Understanding bullying: From research to practice. Canadian Psychology/Psychologie canadienne, 48(2), 86-93.

Cruwys T, Haslam SA, Dingle GA, Jetten J, Hornsey MJ, Desdemona Chong DEM, \& Oei TPS. (2014) Feeling connected again: Interventions that increase social 
This is a peer-reviewed, accepted author manuscript of the following research article: Cresswell-Smith , J., Macintyre, A. K., \& Wahlbeck, K. (2020). Untapped potential? Action by nongovernmental organisations on the social determinants of mental health in high income countries: an integrative review. Voluntary Sector Review, 1-

21. https://doi.org/10.1332/204080520X15874661935482

identification reduce depression symptoms in community and clinical settings, Journal of Affective Disorders, 159:139-146.

Curl A, Kearns A, Mason P, et al. (2015) Physical and mental health outcomes following housing improvements: evidence from the GoWell study. J Epidemiol Community Health, 69:12-19.

Daly, S., \& Allen, J. (2017) Voluntary sector action on the social determinants of health. Institute of Health Equity. Available at http://www.instituteofhealthequity.org/

Daly, M., Bruckhauf, Z., Byrne, J., Pecnik, N., Samms-Vaughan, M., Bray, R., \& Margaria, A. (2015) Family and Parenting Support: Policy and Provision in a Global Context, Innocenti InsightsUNICEF Office of Research - Innocenti, Florence.

Danishevskiy, K., \& McKee, M. (2017) The Russian Anti-Tobacco Advocacy Coalition (ATACa) In: Greer, S.L., Wismar, M., Pastorino, G., et al., editors. Civil society and health: Contributions and potential [Internet]. Copenhagen (Denmark): European Observatory on Health Systems and Policies; 2017. (Observatory Studies Series, No. 48.) Chapter 4.

Delisle, H., Roberts, J. H., Munro, M., Jones, L., \& Gyorkos, T. W. (2005) The role of NGOs in global health research for development. Health Research Policy and Systems, 3(1), 3 .

Department for Children, Schools and Families. Targeted Mental Health in Schools Project. Accessed on 13.5.2019 at https://dera.ioe.ac.uk/28416/1/007842008bkt-en.pdf

Elliot, I. (2016) Poverty and mental health: a review to inform the Joseph Rountree Foundations Anti-Poverty Strategy. London: Mental health Foundation

EUROSTAT Statistics Explained Retrieved on 5 October 2018 from https://ec.europa.eu/eurostat/statisticsExplained/index.php?title=Archive:Housing_conditions

Fisher M, \& Baum F. (2010) The Social Determinants of Mental Health: Implications for Research and Health Promotion. Australian \& New Zealand Journal of Psychiatry, 44(12):1057-1063. 
This is a peer-reviewed, accepted author manuscript of the following research article: Cresswell-Smith , J., Macintyre, A. K., \& Wahlbeck, K. (2020). Untapped potential? Action by nongovernmental organisations on the social determinants of mental health in high income countries: an integrative review. Voluntary Sector Review, 1-

21. https://doi.org/10.1332/204080520X15874661935482

Flanagan, S.M., \& Hancock, B. (2010) 'Reaching the hard to reach' - lessons learned from the VCS (Voluntary and Community Sector). A qualitative study. BMC Health Serv Res, 10, 92-92.

Forsman AK, Wahlbeck K, Aarø LE, Alonso J, Barry MM, Brunn M, et al. and the ROAMER Consortium. (2015) Research priorities for public mental health in Europe: recommendations of the ROAMER project. Eur J Public Health, Apr; 25(2):249-54.

Fragar, L., Kelly, B., Peters, M., Henderson, A., \& Tonna, A. (2008), Partnerships to promote mental health of NSW farmers: The New South Wales Farmers Blueprint for Mental Health. Australian Journal of Rural Health, 16: 170-175.

Gardner, F., Burton, J., \& Klimes, I. (2006) Randomised controlled trial of a parenting intervention in the voluntary sector for reducing child conduct problems: outcomes and mechanisms of change. Journal of Child Psychology and Psychiatry, 47: 1123-1132.

Gentry, S. V., Powers, E. F. J., Azim, N., \& Maidrag, M. (2018) Effectiveness of a voluntary family befriending service: a mixed methods evaluation using the Donabedian model. Public Health, 160, 87-93.

Green, G., \& Gilbertson, J. (2008) Warm front: better health: Health impact evaluation of the warm front scheme. Sheffield: Sheffield Hallam University, Centre for Regional Social and Economic Research.

Greer, S.L., Kosinska, M., \& Wismar, M. (2017) What civil society does in and for health: a framework. In: Greer, S.L., Wismar, M., Pastorino, G., et al., editors. Civil society and health: Contributions and potential [Internet]. Copenhagen (Denmark): European Observatory on Health Systems and Policies; (Observatory Studies Series, No. 48.) Chapter 1.Available from: https://www.ncbi.nlm.nih.gov/books/NBK459034/

Greer, S.L., Wismar, M., Pastorino, G., \& Kosinska, M. (2017). Civil Society and Health; Contributions and Potential. European Observatory on Health Systems and Policies. World Health Organization 2017 Available at http://www.euro.who.int/en/publications/abstracts/civil-society-and-healthcontributions-and-potential-2017 
This is a peer-reviewed, accepted author manuscript of the following research article: Cresswell-Smith , J., Macintyre, A. K., \& Wahlbeck, K. (2020). Untapped potential? Action by nongovernmental organisations on the social determinants of mental health in high income countries: an integrative review. Voluntary Sector Review, 1-

21. https://doi.org/10.1332/204080520X15874661935482

Harvey, S., Henderson, M., Lelliott, P., \& Hotopf, M. (2009) Mental health and employment: Much work still to be done. British Journal of Psychiatry, 194(3), 201-203

Hayes K, Berry P, \& Ebi KL. (2019) Factors Influencing the Mental Health Consequences of Climate Change in Canada. Int J Environ Res Public Health, 16(9):1583. Published 2019 May 6. doi:10.3390/ijerph16091583

Helbich M. (2018) Toward dynamic urban environmental exposure assessments in mental health research. Environ Res,161:129-135. doi:10.1016/j.envres.2017.11.006

Hermanns, J. M. A., Asscher, J. J., Zijlstra, B. J. H., Hoffenaar, P. J., \& Dekovič, M. (2013) Long-term changes in parenting and child behavior after the Home-Start family support program. Children and Youth Services Review, 35(4), 678-684.

Jareg, P., \& Kaseje, D. (1998) Growth of civil society in developing countries: implications for health. The Lancet.351:819-22.

Jenkins, R., Fitch, C., Hurlston, M., \& Walker, F. (2009) Recession, debt and mental health: challenges and solutions. Mental health in family medicine, 6(2), 85-90.

Jané-Llopis E, Anderson P, Stewart-Brown S, Weare K, Wahlbeck K, McDaid D, Cooper C, \& Litchfield P. (2011) Reducing the silent burden of impaired mental health. J Health Commun,16(2):59-74.

Johnson, S. (2017) Social interventions in mental health: a call to action. Soc Psychiatry Psychiatr Epidemiol, 52: 245.

Joint Action on Mental Health and Well-being, Mental Health in all Policies (2017). Situation analysis and recommendations for action. Retrieved 15 October 2018 from

https://ec.europa.eu/health/sites/health/files/mental_health/docs/2017_mh_allpol icies_en.pdf

Jones, M., Kimberlee, R., Deave, T., \& Evans, S. (2013) The Role of Community Centre-based Arts, Leisure and Social Activities in Promoting Adult Well-being and Healthy Lifestyles. International Journal of Environmental Research and Public Health, 10(5), 1948-1962.

Karlsson, M., \& Markström, U. (2012) Non-Profit Organizations in Mental Health: Their Roles as seen in Research. Voluntas, 23(2), 287-301. 
This is a peer-reviewed, accepted author manuscript of the following research article: Cresswell-Smith , J., Macintyre, A. K., \& Wahlbeck, K. (2020). Untapped potential? Action by nongovernmental organisations on the social determinants of mental health in high income countries: an integrative review. Voluntary Sector Review, 1-

21. https://doi.org/10.1332/204080520X15874661935482

Kearns A, Whitley E, Tannahill C, Ellaway A.(2015) Loneliness, social relations and health and well-being in deprived communities. Psychol Health Med, $20(3): 332-344$

Larsson, M., Pettersson, C., Skoog, T., \& Eriksson, C. (2016) Enabling relationship formation, development, and closure in a one-year female mentoring program at a non-governmental organization: a mixed-method study. BMC Public Health, 16,179 .

Lee, A.C.K., \& Maheswaran, R. (2010) The health benefits of urban green spaces: a review of the evidence. Journal of Public Health 33(2), 212-222.

Markström, U., \& Karlsson, M. (2013) Towards Hybridization: The Roles of Swedish Non-Profit Organizations within Mental Health. Voluntas 24: 917

Marmot, M. (2005) Social determinants of health inequalities. The Lancet, 365 (9464), $1099-1104$.

Marmot, M., Friel, S., Bell, R., Houweling, T.A.J., \& Taylor, S. (2008) Closing the gap in a generation: health equity through action on the social determinants of health. The Lancet, 372 (9650), 1661 - 1669.

Marmot, M., Geddes, I., Bloomer, E., Allen, J., \& Goldblatt, P. (2011) The health impacts of cold homes and fuel poverty. London: Friends of the Earth \& the Marmot Review Team. Retrieved on 5 June 2018 from http://www.instituteofhealthequity.org/resources-reports/the-health-impacts-ofcold-homes-and-fuel-poverty/the-health-impacts-of-cold-homes-and-fuelpoverty.pdf

Mason, K. E., Baker, E., Blakely, T., \& Bentley, R. J. (2013) Housing affordability and mental health: Does the relationship differ for renters and home purchasers? Social Science \& Medicine, 94, 91-97.

Matthews, P, \& Besemer, K. (2014) Poverty and social networks evidence review. Joseph Rowntree Foundation. University of Stirling.

Mattheys, K., Bambra, C., Warren, J., Kasim, A., \& Akhter, N. (2016) Inequalities in mental health and well-being in a time of austerity: Baseline findings from the Stockton-on-Tees cohort study. SSM Popul Health,2:350-359.

Mead, N., Lester, H., Chew-Graham, C., Gask, L., \& Bower, P. (2010) Effects of befriending on depressive symptoms and distress: systematic review and meta- 
This is a peer-reviewed, accepted author manuscript of the following research article: Cresswell-Smith , J., Macintyre, A. K., \& Wahlbeck, K. (2020). Untapped potential? Action by nongovernmental organisations on the social determinants of mental health in high income countries: an integrative review. Voluntary Sector Review, 1-

21. https://doi.org/10.1332/204080520X15874661935482

analysis. The British Journal of Psychiatry: The Journal of Mental Science, 196(2), 96-101.

Mental Health and Debt Guidelines. MALG Good Practice Awareness Guidelines for Helping Consumers with Mental Health Conditions \& Debt. Available at http://malg.org.uk/resources/malg-mental-health-and-debt-guidelines/ accessed on 23.6.2019

Mental Health Foundation (2007) Listen Up! Person-centred approaches to help young people experiencing mental health and emotional problems. London: MHF.

Mulvale, G., Chodos, H., Bartram, M., MacKinnon, M. P., \& Abud, M. (2014) Short report: Engaging civil society through deliberative dialogue to create the first Mental Health Strategy for Canada: Changing Directions, Changing Lives. Social Science \& Medicine, 123, 262-268.

Newton, B., Meager, N., Bertram, C., Corden, A., George, A., Lalani, M., Metcalf, H., Rolfe, H., Sainsbury, R. and Weston, K. (2012) Work Programme Evaluation: Findings from the First Phase of Qualitative Research on Programme Delivery, London: Department for Work and Pensions.

Nieminen, T., Martelin, T., Koskinen, S., Aro, H., Alanen, E., \& Hyyppä, M. T. (2010) Social capital as a determinant of self-rated health and psychological well-being. International Journal of Public Health, 55(6), 531-542.

OECD (2012) Sick on the job? myths and realities about mental health and work, OECD Publishing, Paris

OECD (2012), Equity and Quality in Education: Supporting Disadvantaged Students and Schools, OECD Publishing. http://dx.doi.org/10.1787/9789264130852-en

OECD. PISA 2015 results. Vol I: Excellence and Equity in Education (OECD, 2016). O'Rourke HM, \& Sidani S. (2017) Definition, Determinants, and Outcomes of Social Connectedness for Older Adults: A Scoping Review. J Gerontol Nurs,43(7):4352.

Olivier C, Hunt M., R. \& Ridde V. NGO-researcher partnerships in global health research: benefits, challenges, and approaches that promote success. Dev Pract. 2016 26:4, 444-455, Available at DOI: 10.1080/09614524.2016.1164122

Pickett, K., \& Wilkinson, R. (2010) Inequality: An under acknowledged source of mental illness and distress. British Journal of Psychiatry, 197(6), 426-428. 
This is a peer-reviewed, accepted author manuscript of the following research article: Cresswell-Smith , J., Macintyre, A. K., \& Wahlbeck, K. (2020). Untapped potential? Action by nongovernmental organisations on the social determinants of mental health in high income countries: an integrative review. Voluntary Sector Review, 1-

21. https://doi.org/10.1332/204080520X15874661935482

Reiss, F. (2013) Socioeconomic inequalities and mental health problems in children and adolescents: A systematic review. Social Science \& Medicine, 90(C), 24-31.

Rose, G., von Hippel, C., Brener, L., \& von Hippel, B. (2018) Attitudes of people working in mental health non-governmental organisations in Australia: A comparison with other mental health professionals. Health psychology Open, 5(1), 2055102918765413.

Samaritans, (2017) Dying from inequality. Socioeconomic disadvantage and suicidal behaviour. Samaritans: Ewell, Surrey

Savage J. Mental Health and Housing. Mental Health Foundation. Policy Paper 2016

Shandas, V., \& Messer, W.B. (2008) Fostering green communities through civic engagement: Community-based environmental stewardship in the Portland area. Journal of the American Planning Association 74(4), 408-418.

Shelter Public Perceptions of Housing and Mental Health Survey. Shelter, in partnership with ComRes 2017. Retrieved 16 March 2018 from http://www.comresglobal.com/polls/shelter-housing-mental-health-survey/

Shim, R., Koplan, C., Langheim, F. J. P., Manseau, M. W., Powers, R. A., \& Compton, M. T. (2014) The social determinants of mental health: An overview and call to action. Psychiatric Annals, 44(1), 22-26.

Silva, M., Loureiro, \& A., Cardoso, G. (2016) Social determinants of mental health: a review of the evidence. European Journal of Psychiatry, 30, 259-292.

Small, M. L. (2010) Unanticipated Gains: Origins of Network Inequality in Everyday Life (Reprint edition). New York: Oxford University Press.

Smith, M., Albanese, F., \& Truder, J. (2014) A Roof over My Head: the final report of the Sustain project, a Longitudinal study of housing outcomes and wellbeing in private rented accommodation. London: Shelter and Crisis. Retrieved 12 June 2018 from http://england.shelter.org.uk/_data/assets/pdf_file/0005/760514/6424_Sustain_ Final_Report_for_web.pdf

Spratt, J., Shucksmith, J., Philip, K. \& Watson, C. (2007) Embedded yet separate: Tensions in voluntary sector working to support mental health in state-run schools. Journal of Education Policy, 22(4): 411-28. Stewart-Brown, S.L., Schrader-McMillan, A. (2011) Parenting for mental health: what does the 
This is a peer-reviewed, accepted author manuscript of the following research article: Cresswell-Smith , J., Macintyre, A. K., \& Wahlbeck, K. (2020). Untapped potential? Action by nongovernmental organisations on the social determinants of mental health in high income countries: an integrative review. Voluntary Sector Review, 1-

21. https://doi.org/10.1332/204080520X15874661935482

evidence say we need to do? Report of Workpackage 2 of the DataPrev project. Health Promot Int, 26(1):i10-i28

Thomas, P,A., Liu, H., \& Umberson, D. (2017) Family Relationships and WellBeing. Innov Aging, 1(3):igx025. doi:10.1093/geroni/igx025

Thompson, R., Valenti, E., Siette, J., \& Priebe, S. (2016). To befriend or to be a friend: A systematic review of the meaning and practice of 'befriending' in mental health care. Journal of Mental Health, 25(1), 71-77.

Torraco, R.(2016) Writing Integrative Literature Reviews: Using the Past and Present to Explore the Future. Human Resource Development Review,15(4),404-428 Townsend, M., \& Weerasuriya, R. (2010). Beyond Blue to Green: The benefits of contact with nature for mental health and well-being. Beyond Blue Limited: Melbourne, Australia.

United Nations Human Rights Council, Report of the Special Rapporteur on the right of everyone to the enjoyment of the highest attainable standard of physical and mental health, 28 March 2017, A/HRC/35/21, available at: https://www.refworld.org/docid/593947e14.html [accessed 9 September 2019]

Berg, A. E. v. d., Maas, J., Verheij, R. A., \& Groenewegen, P. P. (2010). Green space as a buffer between stressful life events and health. Social Science and Medicine, 70(8), 1203-1210. van Aar, J. V., Asscher, J. J., Zijlstra, B. J. H., Deković, M., \& Hoffenaar, P. J. (2015) Changes in parenting and child behavior after the home-start family support program: A 10year follow-up. Children and Youth Services Review, 53(C), 166-175.

Victor, C.R., \& Yang, K. (2012) The prevalence of loneliness among adults: a case study of the United Kingdom. The Journal of psychology, 146(1-2):85-104.

Wahlbeck, K. (2015) Public mental health: the time is ripe for translation of evidence into practice. World Psychiatry,14(1):36-42.

Wahlbeck, K., Cresswell-Smith, J., Haaramo, P., \& Parkkonen, J. (2017). Interventions to mitigate the effects of poverty and inequality on mental health. Social Psychiatry and Psychiatric Epidemiology, 52(5), 505-514.Watts, N., Amann, M., Ayeb-Karlsson, S., Belesova, K., Bouley, T., Boykoff, M., \& Byass, P. et al. (2018) The Lancet Countdown on health and climate change: from 25 years of 
This is a peer-reviewed, accepted author manuscript of the following research article: Cresswell-Smith , J., Macintyre, A. K., \& Wahlbeck, K. (2020). Untapped potential? Action by nongovernmental organisations on the social determinants of mental health in high income countries: an integrative review. Voluntary Sector Review, 1-

21. https://doi.org/10.1332/204080520X15874661935482

inaction to a global transformation for public health. The Lancet, 91(10120):581-630,doi.org/10.1016/S0140-6736(17)32464-9.

Weare, K. (2010) Mental health and social and emotional learning: evidence, principles, tensions, balances. Adv School Ment Health Promot,3:5-17

Weare, K., \& Nind, M. (2011) Mental health promotion and problem prevention in schools: what does the evidence say? Health Promotion International, 26 (1); i29-69.

World Health Organisation. (2003) Mental Health Policy and Service Guidance Package. The Mental Health Context. Retrieved on 13 February 2018 from https://www.who.int/mental_health/resources/en/context.PDF

World Health Organisation (2005) Mental health policies and programmes in the workplace. Geneva, World Health Organization

World Health Organisation. (2007) Civil Society Report, Commission on Social Determinants of Health. Retrieved 1 March 2018, from http://www.who.int/social_determinants/publications/civilsociety/en/

World Health Organisation. (2013) Health 2020: A European policy framework supporting action across government and society for health and well-being. WHO Regional Office for Europe.

World Health Organisation. (2014) Health in All Policies: Framework for Country Action. Retrieved April 20198 from https://www.who.int/healthpromotion/frameworkforcountryaction/en/

World Health Organization and Calouste Gulbenkian Foundation. (2014). Social determinants of mental health. Geneva, World Health Organization.

Yan, X., Lin, H., \& Clarke, A. (2018). Cross-Sector Social Partnerships for Social Change: The Roles of Non-Governmental Organizations. Sustainability, 10(2), 558.

Zachariah, R., Ford, N., Draguez B., Yun O \& Reida, T. Conducting Operational Research within a Non-Governmental Organization: The Example of Médecins Sans Frontières. International Health. 2010 2: 1-8. doi:

10.1016/j.inhe.2009.12.008 